\title{
Caracterização físico-química dos biodieseis dos óleos de coco, soja e maracujá obtidos por transesterificação utilizando ultrassom
}

O presente estudo trata da produção dos biodieseis dos óleos de coco, soja e maracujá obtidos por transesterificação utilizando ultrassom, assim como sua caracterização físico-química. Os óleos de coco e soja foram adquiridos no comércio varejista, e o óleo de maracujá foi produzido em Laboratório na Universidade Federal Fluminense. O processo de transesterificação se deu com o uso do ultrassom Cole Parmer $750 \mathrm{~W}$. Verificou-se o rendimento dos biodieseis produzidos em relação ao volume de óleo utilizado nas bateladas. Foram feitas misturas do biodiesel produzido com o óleo diesel nas proporções B0, B25, B50, B75 e B100. As misturas foram caracterizadas através das propriedades físico-químicas: viscosidade cinemática a $40^{\circ} \mathrm{C}$; massa específica a $20^{\circ} \mathrm{C}$; ponto de névoa e ponto de fluidez A massa específica das misturas foi determinada por meio do Método do Picnômetro, sendo encontrados valores de massa específica entre $832,166 \mathrm{~kg} / \mathrm{m} 3$ a $20^{\circ} \mathrm{C}$ para o diesel (B0) e $884,619 \mathrm{~kg} / \mathrm{m} 3$ a $20^{\circ} \mathrm{C}$ para o biodiesel de maracujá (B100), confirmando o aumento da massa específica em relação ao aumento do biodiesel nas misturas. A viscosidade cinemática das misturas, também, apresentou valores maiores com o acréscimo do biodiesel nas misturas. $\mathrm{O}$ biodiesel de coco apresentou ponto de névoa elevado $\left(7,20^{\circ} \mathrm{C}\right)$ sendo este valor superior ao verificado em outros biodieseis e no diesel.

\section{Physicochemical characterization of the biodiesels of coconut, soybean and passion fruit oils obtained by transesterification using ultrasound}

The present study deals with the production of coconut oil, soybean and passion fruit biodiesels obtained by transesterification using ultrasound, as well as their physicochemical characterization. Coconut and soybean oils were purchased in the retail trade, and passion fruit oil was produced in a laboratory at the Fluminense Federal University. The transesterification process took place using the Cole Parmer $750 \mathrm{~W}$ ultrasound. The yield of the biodiesel produced in relation to the volume of oil used in the batches was verified. Mixtures of biodiesel produced with diesel oil in the proportions BO, B25, B50, B75 and B100 were made. The mixtures were characterized by physicochemical properties: kinematic viscosity at $40^{\circ} \mathrm{C}$; specific mass at $20^{\circ} \mathrm{C}$; fog point and pour point. The specific mass of the mixtures was determined using the Pycnometer Method, and specific mass values were found between $832.166 \mathrm{~kg} / \mathrm{m} 3$ at $20^{\circ} \mathrm{C}$ for diesel (BO) and $884.619 \mathrm{~kg} / \mathrm{m} 3$ at $20^{\circ} \mathrm{C}$ for passion fruit biodiesel ( B100), confirming the increase of specific mass in relation to the increase of biodiesel in the mixtures. The kinematic viscosity of the mixtures also presented higher values with the addition of biodiesel in the mixtures. Coconut biodiesel had a high fog point $\left(7,20^{\circ} \mathrm{C}\right)$, which is higher than that observed in another biodiesel and diesel.

Keywords: Biodiesel; Diesel; Kinematic Viscosity; Especific Mass; Fog Point.

Topic: Engenharia Ambiental

Reviewed anonymously in the process of blind peer.
Received: $17 / 06 / 2018$

Approved: 28/09/2018
Ivenio Moreira da Silva (iD)

Universidade Federal Fluminense, Brasil

http://lattes.cnpq.br/8851564731097828

http://orcid.org/0000-0003-0776-7565

ivenio.turmas@gmail.com

Roberto Guimarães Pereira (10)

Universidade Federal Fluminense, Brasil

http://lattes.cnpq.br/9607255646013062

http://orcid.org/0000-0001-6094-1396

temrobe@vm.uff.br
Referencing this:

SILVA, I. M.; PEREIRA, R. G.. Caracterização físico-química dos biodieseis dos óleos de coco, soja e maracujá obtidos por transesterificação utilizando ultrassom. Natural Resources, v.8, n.2, p.11-20, 2018. DOI: http://doi.org/10.6008/CBPC2237$\underline{9290.2018 .002 .0002}$ 


\section{INTRODUÇÃO}

A população humana mundial, segundo Rozina et al. (2017), atingiu 7,324bi até 2015, e esse rápido aumento da população está ampliando as demandas de energia em todo o mundo, levando à busca de fontes alternativas de energia. Devido ao estoque finito de combustíveis fósseis e seu impacto negativo sobre o meio ambiente, muitos países em todo o mundo estão agora investindo no uso de energias renováveis, como energia solar, energia eólica, biocombustíveis, energia hidrelétrica, energia geotérmica e oceânica para garantir energia para o desenvolvimento dos países (MAHMUDUL et al., 2017).

Nesse enfoque, segundo Joshi et al. (2017), a Índia iniciou um dos maiores programas de energia alternativa do mundo, incluindo energia solar, energia eólica, energia hidrelétrica, energia de biomassa, etc.. Entre elas, a energia de biomassa foi considerada como a fonte mais promissora, como alternativa ao uso do petróleo. De acordo com Demirbas (2007), biocombustíveis são combustíveis líquidos ou gasosos e são produzidos a partir de fontes renováveis, como óleo vegetal e biomassa. O biodiesel é um biocombustível renovável, biodegradável e com propriedades similares do combustível diesel fóssil (MAHMUDUL et al., 2017).

Ao longo das últimas décadas, a ciência dos biocombustíveis sofreu grandes mudanças em relação à sua taxa de desenvolvimento, foco e países contribuintes. Azadi et al. (2017) analisou a evolução da ciência dos biocombustíveis através de 49 mil artigos (compreendendo 0,26\% de todas as publicações em ciências físicas e da vida) publicados entre 1990 e 2014. O estudo apresentou contribuições científicas de diferentes países para a ciência sobre biocombustíveis, e as principais fontes de matérias primas. Destacando que dentre estas, a Jatropha e óleo de palma foram os mais estudados, seguidos de soja milho e colza.

A produção de biodiesel por meio de algas vem sendo estudada. Oliveira et al. (2014) apresentou uma revisão da literatura sobre as tecnologias de produção de algas aplicadas à produção de biodiesel, sendo destacada a necessidade de pesquisas tecnológicas visando o alinhamento das técnicas de crescimento de microalgas, técnicas extração, separação do óleo, de modo que a produção seja contínua, visando a implantação de processos mais avançados com o intuito de minimizar os custos de produção os métodos de plantio, cultivo e extração.

Guldhe et al. (2014) produziu biodiesel de algas (Scenedesmus sp.) in situ, por meio de micro-ondas e ultrassom. Naquele estudo, estacou-se como vantagem, um indicativo de redução de custos do processo por trabalhar em baixas temperaturas $\left(50^{\circ} \mathrm{C}\right)$, mesmo tendo sido encontrados valores de $71 \%$ para a conversão de Scenedesmus sp. em biodiesel via ultrassom e uma variação de aproximadamente $5 \%$ via microondas.

Wang et al. (2013) produziu biodiesel a partir da alga Tribonema minus que fora cultivada durante 21 dias. A transesterificação se deu sob a proporção molar de metanol para óleo de 12:1 durante a catálise com $2 \%$ de hidróxido de potássio a $65^{\circ} \mathrm{C}$ durante $30 \mathrm{~min}$, e taxa de conversão de triacilgliceróis atingiu $96,52 \%$. Dentre as conclusões do trabalho, pôde se observar o potencial da alga Tribonema minus para a produção de biodiesel. 
O processo comercial referente à produção de biodiesel a partir de microalgas fora estudado por Su et al. (2017). Nesse contexto, foram investigadas as barreiras das tecnologias, especialmente a parte extensiva de energia e o teste de escala piloto, que é a parte crucial do processo, bem como o apoio e efeitos de políticas da indústria de biocombustíveis de microalgas, americanas, europeias e chinesas.

Através do estudo, constatou-se numerosos programas de escala piloto apoiados pelo governo e o investimento privado. Contudo, ainda há alguma distância da produção em escala. Segundo os autores, a estratégia chave para a produção e comercialização do biodiesel de algas está nas pesquisas referentes à biologia das algas, a produção de co-produtos para fazer lucros em curto prazo e o apoio do governo. Feroldi et al. (2012) estudou o cultivo e beneficiamento do crambe, visando contribuir na produção de biodiesel nas estações de outono e inverno.

Investigou-se a produção de biodiesel a partir do óleo do coco da Macaúba usando uma lipase comercial sob a influência do ultrassom (MICHELIN et al., 2015), sendo observado um rendimento máximo "teórico" de ésteres de 80,1\%, mediante os parâmetros de conversibilidade e eficiência de conversão. Parida et al. (2017) realizou a transesterificação de óleo de soja sob aplicação de ultrassom. Naquela oportunidade foram investigados os efeitos dos vários parâmetros de reação na transesterificação, como a relação molar metanol/óleo, a concentração do co-solvente e a quantidade do catalisador utilizado. Dentre os resultados, registrou-se a conversão de $92 \%$ de ésteres metílicos de ácidos graxos com meia hora usando uma quantidade estequiométrica de álcool (razão molar álcool / óleo 3:1), 1\% em peso de catalisador e ultrassom em $20 \mathrm{kHz}$ e $30 \%$ em peso do Diesel co-solvente.

Paiva et al. (2013) produziu biodiesel por ultrassom, a partir do óleo de babaçu. O processo se deu por catálise alcalina para viabilizar a produção verde de biodiesel com métodos simples e tecnologia disponível. A relação molar de etanol/óleo influenciou decisivamente o processo, sendo as maiores conversões a $30^{\circ} \mathrm{C}$ com aproximadamente $1,0 \%$ em peso de hidróxido, com melhores resultados mediante a utilização de $\mathrm{KOH}$ invés de $\mathrm{NaOH}$. Alinhado com a tendência mundial de se utilizar biocombustíveis, o presente estudo trata da caracterização físico-química dos biodieseis dos óleos de Coco, soja e Maracujá obtidos por transesterificação utilizando ultrassom.

\section{MATERIAIS E MÉTODOS}

\section{Produção do biodiesel por ultrassom}

O biodiesel foi produzido a partir dos óleos de soja e coco, adquiridos no comércio varejista, e a partir do óleo de maracujá extraído no Laboratório de Processamento de Produtos Agrícolas do Departamento de Engenharia Agrícola e Meio Ambiente da UFF. O processo de transesterificação se deu com o uso do álcool metílico e do catalisador $\mathrm{NaOH}$ a $1 \%$, procedendo a reação com o uso do ultrassom Cole Parmer 750 , ilustrado na figura 1. No presente estudo trabalhou-se com bateladas de $100 \mathrm{~mL}$ configurando o equipamento da seguinte forma: ajuste do tempo efetivo de ação de 20 minutos; temperatura de $45^{\circ} \mathrm{C}$ durante o processo; intervalo de pulsação de $2 / 1$ segundos; e amplitude de $35 \%$. 


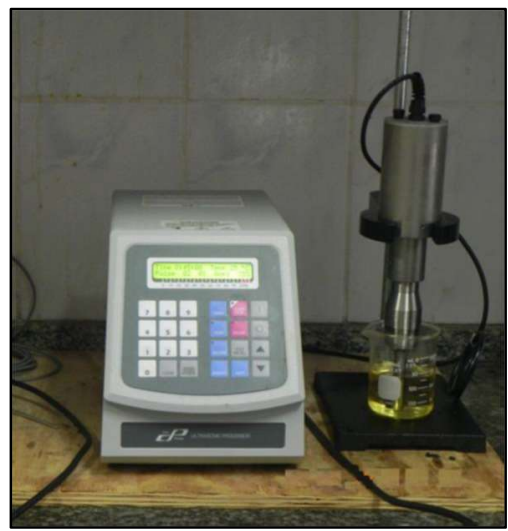

Figura 1: Ultrassom Cole Parmer 750W.

\section{Produção dos biodieseis de Óleo de Coco e Óleo de Soja}

O experimento foi conduzido em razão molar de 6:1, adotando-se bateladas de $100 \mathrm{~mL}$ de óleo. Passado o tempo previsto em que a mistura esteve sob ação do ultrassom, a mesma foi transferida para um funil de decantação com capacidade para $500 \mathrm{~mL}$ onde permaneceu por $24 \mathrm{~h}$ para a separação da glicerina. 0 biodiesel produzido foi posteriormente lavado e armazenado em frascos âmbar, com capacidade para um litro, permanecendo em local isento de luz e arejado. Os procedimentos que envolveram manipulação de produtos químicos foram executados em capela com sistema de exaustão, conforme figura 2 . A rotina de produção do biodiesel por ultrassom é mostrada na figura 3.

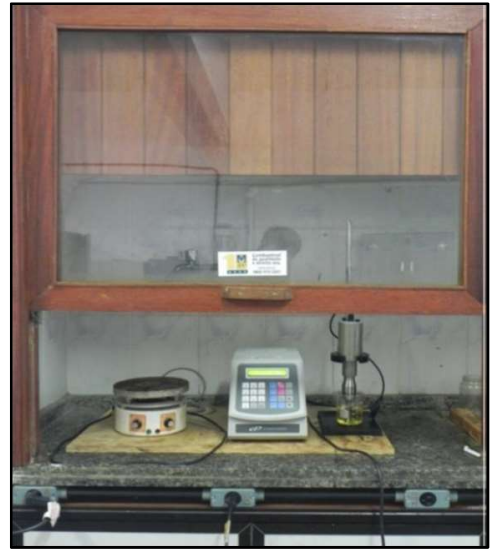

Figura 2: Capela com sistema de exaustão.

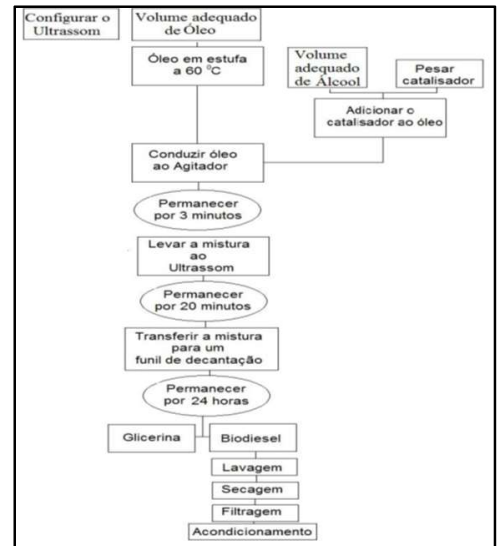

Figura 3: Fluxograma da Produção de Biodiesel por Ultrassom.

\section{Preparo das misturas e propriedades físico-químicas do biodiesel}

O biodiesel produzido foi fracionado e misturado ao óleo diesel nas seguintes proporções em volume: Diesel 100\%; Biodiesel 25\% e Diesel 75\%; Biodiesel 50\% e Diesel 50\%; Biodiesel 75\% e Diesel 25\%; e Biodiesel 100\%. Tais misturas foram denominadas B0, B25, B50, B75 e B100, respectivamente e acondicionadas em frascos de cor âmbar (figura 4). As propriedades físico-químicas determinadas foram: Viscosidade Cinemática a $40^{\circ} \mathrm{C}$, Massa Específica a $20^{\circ} \mathrm{C}$, Ponto de Névoa e Ponto de Fluidez, seguindo as Normas indicadas no quadro 1. 


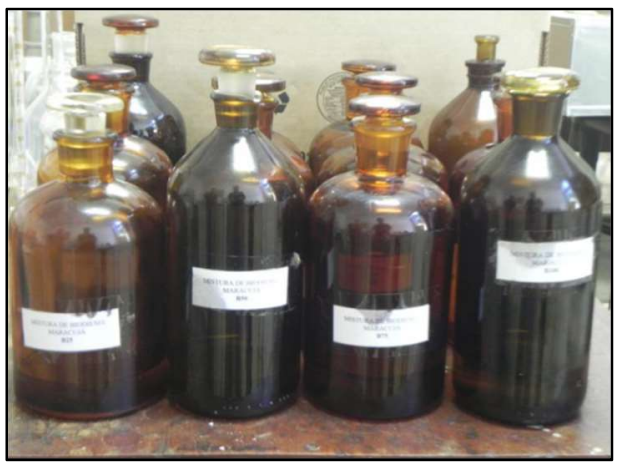

Figura 4: Misturas de biodiesel guardadas em frascos de vidro de cor âmbar.

Quadro 1: Propriedades físico-químicas determinadas.

\begin{tabular}{|l|l|}
\hline Propriedade & Norma \\
\hline $\begin{array}{l}\text { Viscosidade } \\
\text { Cinemática }\end{array}$ & $\begin{array}{l}\text { NBR 10441 Produtos de petróleo - Líquidos transparentes e opacos - Determinação da Viscosidade } \\
\text { Cinemática e cálculo da Viscosidade Dinâmica }\end{array}$ \\
\hline Massa Específica & $\begin{array}{l}\text { ASTM D 4052: Density and Relative Density of liquids by Digital Density meter. } \\
\text { Norma no NIE-DIMEL-039/INMETRO - Determinação de Massa Específica utilizando o picnômetro. }\end{array}$ \\
\hline Ponto de Névoa & ASTM D2500 Test Method for Cloud Point of Petroleum Products \\
\hline Ponto de Fluidez & ASTM D97 Test Method for Pour Point of Petroleum Products \\
\hline
\end{tabular}

\section{Viscosidade Cinemática}

A viscosidade Cinemática do biodiesel produzido foi determinada utilizando um viscosímetro tipo Cannon Fenske, capilar100, constante $\mathrm{K}=0,01512 \mathrm{~mm}^{2} / \mathrm{s}^{2}$ (figura 5). O combustível foi transferido para o viscosímetro e em seguida levado ao banho termostático a $40^{\circ} \mathrm{C}$ (figura 6), seguindo a NBR 10441 . O valor da viscosidade de cada mistura em $\mathrm{mm}^{2} / \mathrm{s}$, foi obtido multiplicando-se a média dos tempos registrados em quatro repetições com valores de maior proximidade entre si, pela constante do viscosímetro. A Massa Específica das misturas foi determinada por meio do método do picnômetro, NIE-DIMEL-039/INMETRO, em quatro repetições, como mostra a figura 7.

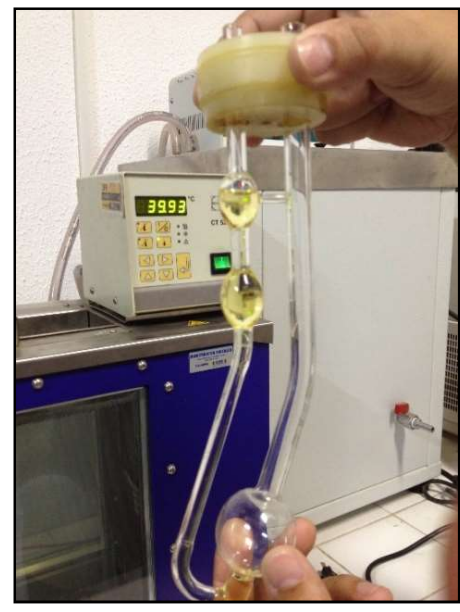

Figura 5: Combustível no Viscosímetro Capilar Kanon Fenske.

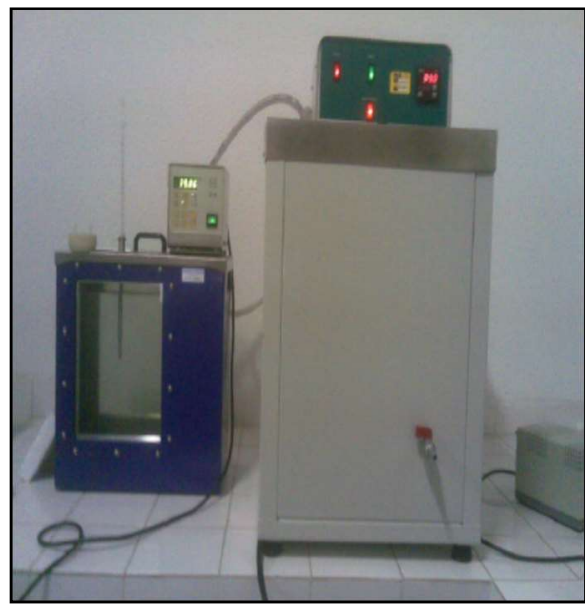

Figura 6: Banho termostático para determinação da viscosidade.

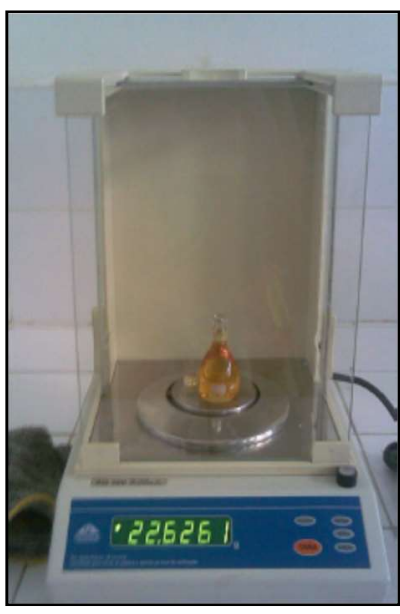

Figura 7: Balança digital com picnômetro.

\section{Calibração do Picnômetro}

Inicialmente o picnômetro foi lavado, e submetido a uma segunda lavagem com éter de petróleo sendo conduzido à estufa a $65^{\circ} \mathrm{C}$ durante cinco horas. Posteriormente, calibrou-se o picnômetro 
completando seu volume com água destilada e pesando-o. Conhecendo-se o valor da Massa Específica da água, chegou-se ao volume real do Picnômetro. Repetiu-se os procedimentos anteriores para confirmação do valor encontrado.

O picnômetro após seco em estufa foi retirado, resfriado em temperatura ambiente e pesado na balança digital. Cada mistura de biodiesel foi inicialmente homogeneizada e colocada no picnômetro, e em seguida, este foi conduzido ao banho termostático, e mantido imerso por 20 minutos, tempo suficiente para o equilíbrio térmico entre o combustível e o fluido do banho termostático. Posteriormente, o picnômetro teve seu exterior cuidadosamente seco sendo levado ao interior da balança de precisão para pesagem. 0 valor da Massa Específica foi obtido dividindo-se o valor de massa registrado na balança pelo volume do picnômetro. Os Pontos de Névoa e Fluidez foram determinados utilizando o Banho de Refrigeração Elcar EL/PN 114-4 (figura 8), seguindo as normas ASTM D2500 e ASTM D97.

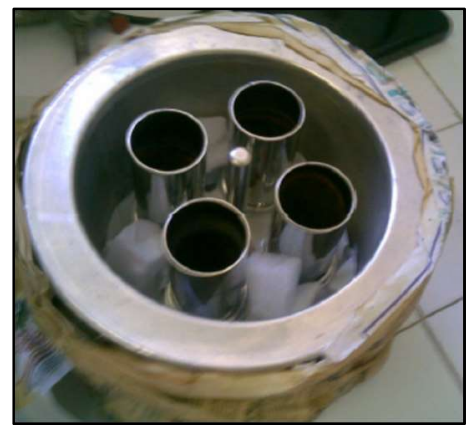

Figura 8: Banho de Refrigeração Elcar para determinação do Ponto de Névoa e Fluidez.

\section{RESULTADOS E DISCUSSÃO}

\section{Rendimento na produção de biodiesel}

O processo de produção do biodiesel de maracujá, soja e coco apresentaram os rendimentos de $75,69 \%$, e $90,63 \%, 83,46 \%$, respectivamente. Araújo et al. (2009) produziram biodiesel de coco com razão molar 1:6, a $60^{\circ} \mathrm{C}$, obtendo um rendimento de 70,65\%. Quessada et al. (2010) encontrou um rendimento de $93,81 \%$ do biodiesel de soja com etanol, e $\mathrm{NaOH}$ a $0,5 \%$.

\section{Caracterização físico-química: Viscosidade Cinemática}

A Viscosidade Cinemática do biodiesel e das misturas de Biodiesel ao diesel S50 apresentou-se dentro dos limites de 3,0 a $6,0 \mathrm{~mm}^{2} / \mathrm{s}$, estabelecidos pela ANP conforme Regulamento Técnico ANP № 3/2014. A Figura 9 mostra que o aumento do percentual de biodiesel na mistura com diesel leva a um aumento no valor da viscosidade da mistura, uma vez que o biodiesel é mais viscoso que o óleo diesel usado no presente estudo. Esse comportamento também foi reportado por Souza et al. (2009), Mejia et al. (2013) e Geller at al. (2008). O controle deste parâmetro de qualidade visa garantir um funcionamento adequado nos sistemas de injeção e nas bombas de combustível. O biodiesel de coco apresentou valores de viscosidade inferiores ao biodiesel de soja e de maracujá, sendo observada uma pequena variação na viscosidade da mistura B25 em relação ao diesel puro. 


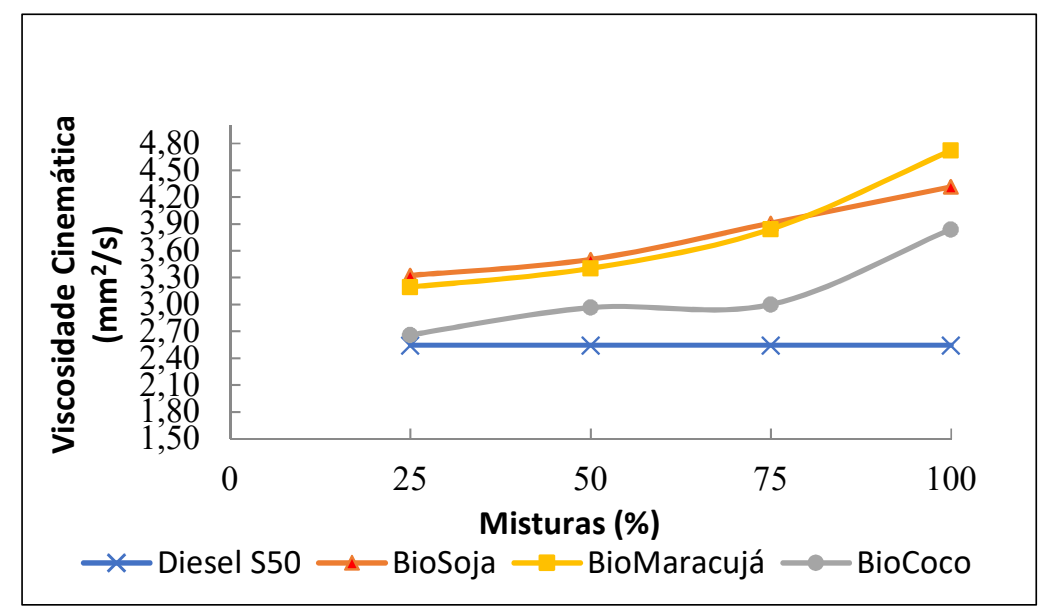

Figura 9: Comportamento da Viscosidade Cinemática das misturas a $40^{\circ} \mathrm{C}$.

\section{Massa Específica: Método do Picnômetro}

Os valores obtidos na determinação da Massa Específica por meio do Picnômetro estão na tabela 1. Conforme previsto, verificou-se o aumento da Massa Específica das misturas à medida que se aumenta a proporção de Biodiesel (figura 10). Segundo Souza et al. (2009), o referido aumento ocorre devido às interações moleculares, visto que o óleo diesel tem na sua composição somente hidrocarbonetos, enquanto que o biodiesel é formado por ésteres. Valores altos de Massa Específica possibilitam um bom funcionamento do motor, com boa lubrificação, evitando entupimentos.

Tabela 1: Massa específica em $\mathrm{kg} / \mathrm{m}^{3}$ a $20^{\circ} \mathrm{C}$

\begin{tabular}{|l|l|l|l|l|}
\hline Amostras & Diesel S50 & BioSoja & BioCoco & BioMaracujá \\
\hline B0 & 832,166 & $/ /$ & $/ /$ & $/ /$ \\
\hline B25 & $/ /$ & 842,028 & 840,061 & 844,381 \\
\hline B50 & $/ /$ & 855,224 & 849,074 & 858,223 \\
\hline B75 & $/ /$ & 867,149 & 857,445 & 871,054 \\
\hline B100 & $/ /$ & 879,836 & 866,911 & 884,619 \\
\hline
\end{tabular}

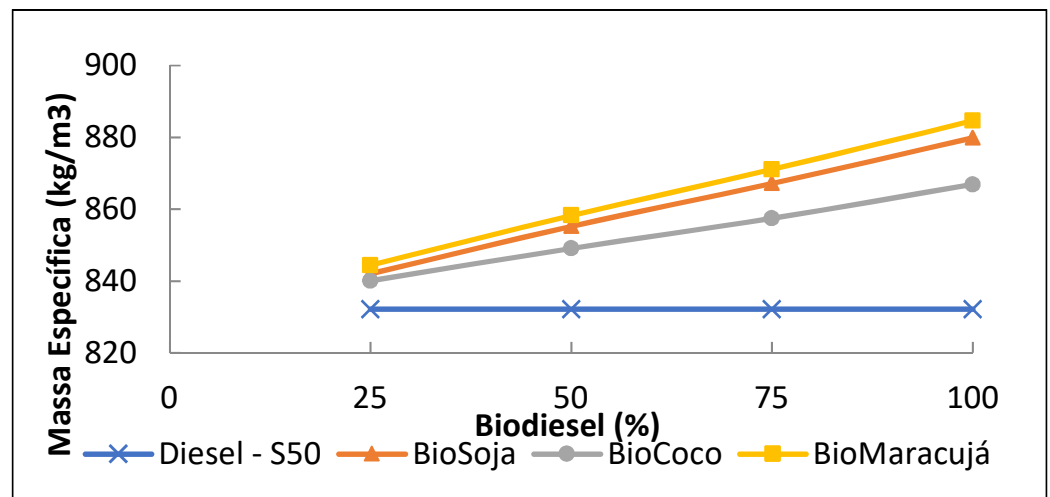

Figura 10: Comportamento da Massa Específica das misturas a $20^{\circ} \mathrm{C}$.

\section{Ponto de Névoa e Ponto de Fluidez}

O Ponto de Névoa verificado nas amostras do Diesel $S 50\left(-2,7^{\circ} \mathrm{C}\right)$ foi próximo ao verificado em outros trabalhos de Sarin et al. (2009) e Tulcán (2010). Contudo, percebe-se que a determinação desta propriedade depende da experiência do executor do ensaio, pois exige atenção na visualização do momento em que há formação de névoa. A busca pelo equilíbrio térmico entre as amostras e o banho ocorre de forma dinâmica e retardos no momento da leitura podem comprometer a confiabilidade dos resultados. 
Para o biodiesel de Soja B100 o Ponto de Névoa (tabela 2) foi de $3,7^{\circ} \mathrm{C}$, valor próximos aos encontrados por Vasconcellos (2009), Dantas (2010) e Tulcán et al. (2010). Foram verificados valores intermediários quando o Biodiesel de soja B100 foi misturado ao Diesel S50. Foi constatado maior Ponto de Névoa do Biodiesel de Coco $\left(7,2^{\circ} \mathrm{C}\right)$, em relação aos demais biodieseis estudados e ao Diesel S50. 0 comportamento do biodiesel de coco às baixas temperaturas, também, foi verificado em outra ocasião por Tulcán et al. (2010), sendo registrada a temperatura de $3^{\circ} \mathrm{C}$. O Ponto de Névoa determinado para o Biodiesel de Maracujá foi de $1,4^{\circ} \mathrm{C}$, valor inferior aos verificados nos demais Biodieseis deste estudo.

O Ponto de Fluidez das misturas manteve a tendência esperada, sendo registradas diferenças inferiores a $10,5^{\circ} \mathrm{C}$ abaixo do Ponto de Névoa das Misturas B100 (tabela 3). Na tabela 4, encontram-se os valores de Ponto de Névoa e Ponto de Fluidez, encontrados para o biodiesel produzido a partir de diversas matérias primas e seus respectivos autores.

Tabela 2: Média do Ponto de Névoa $\left({ }^{\circ} \mathrm{C}\right)$ das Misturas de Biodiesel e Diesel.

\begin{tabular}{|l|l|l|l|l|}
\hline Mistura & Diesel - S50 & BioSoja & BioCoco & BioMaracujá \\
\hline B0 & $-2,7$ & $/ /$ & $/ /$ & $/ /$ \\
\hline B25 & $/ /$ & 1,2 & 4,0 & $-1,0$ \\
\hline B50 & $/ /$ & 1,9 & 4,0 & 0,9 \\
\hline B75 & $/ /$ & 4,2 & 5,0 & 1,2 \\
\hline B100 & $/ /$ & 3,7 & 7,2 & 1,4 \\
\hline
\end{tabular}

Tabela 3: Média do Ponto de Fluidez $\left({ }^{\circ} \mathrm{C}\right)$ das Misturas de Biodiesel e Diesel.

\begin{tabular}{|l|l|l|l|l|}
\hline Mistura & Diesel - S50 & BioSoja & BioCoco & BioMaracujá \\
\hline B0 & $-6,3$ & $/ /$ & $/ /$ & $/ /$ \\
\hline B25 & $/ /$ & $-4,9$ & $-6,3$ & $-6,5$ \\
\hline B50 & $/ /$ & $-4,5$ & $-4,0$ & $-6,7$ \\
\hline B75 & $/ /$ & $-3,1$ & $-3,7$ & $-6,5$ \\
\hline B100 & $-2,2$ & $-3,3$ & $-6,8$ \\
\hline
\end{tabular}

Tabela 4: Ponto de Névoa e Ponto de Fluidez do Biodiesel B100 Produzido a partir de diversas matérias-primas e seus respectivos autores.

\begin{tabular}{|l|c|c|l|}
\hline \multicolumn{1}{|c|}{ Matéria-Prima } & \multicolumn{1}{|c|}{$\begin{array}{c}\text { Ponto de Névoa } \\
\left({ }^{\circ} \mathbf{C}\right)\end{array}$} & $\begin{array}{c}\text { Ponto de Fluidez } \\
\left({ }^{\circ} \mathbf{C}\right)\end{array}$ & \multicolumn{1}{|c|}{ Autores } \\
\hline Diesel & -2 & -16 & Silva (2009) \\
\hline Diesel & 2 & -12 & Tulcán (2010) \\
\hline Biodiesel Soja & -1 & -4 & Dantas (2010) \\
\cline { 2 - 4 } & 6 & -5 & Vasconcelos (2009) \\
\cline { 2 - 4 } & 0 & -6 & Tulcán et al. (2010) \\
\hline \multirow{2}{*}{ Biodiesel de Girassol } & 4 & -9 & Braz (2011) \\
\cline { 2 - 4 } & 2,5 & -10 & Silva (2009) \\
\hline Biodiesel de Palma & 16 & Não disponível & Mejia et al. (2013) \\
\cline { 2 - 4 } & 16 & 12 & Sarin et al (2009) \\
\hline Biodiesel de Mamona & -12 & Não disponível & Mejia et al (2013) \\
\cline { 2 - 4 } & -14 & -26 & Dantas (2010) \\
\cline { 2 - 4 } & -15 & -18 & Vasconcelos (2009) \\
\hline Biodiesel Pinhão Manso & 4 & -3 & Sarin et al. (2009) \\
\hline Biodiesel Coco & 3 & -6 & Tulcán et al. (2010) \\
\hline
\end{tabular}

\section{CONCLUSÕES}

Mediante o crescente interesse pelo uso de energias alternativas, verificou-se que o óleo oriundo das sementes de maracujá pode ser destinado à produção de biodiesel, tendo em vista os valores obtidos das propriedades físico-químicas estudadas. O mesmo ocorre com os biodieseis produzidos com óleo de coco e soja, corroborando com os outros autores. O uso de ultrassom para a produção de biodiesel é uma 
tecnologia que permite agilidade na produção, o que significa a possibilidade de redução de custos com a mão de obra envolvida.

\section{REFERÊNCIAS}

ARAÚJO, G. S.; CARVALHO, R. H. R.; SOUSA, E. M. B. D.. Produção de Biodiesel a partir de Óleo de Coco (Cocos nucifera L.) Bruto. In: INTERNATIONAL WORKSHOP ADVANCES IN CLEANER PRODUCTION, 2. Anais. São Paulo: 2009.

AZADI, P.; MALINA, R.; BARRETT, S. R. H.; KRAFT, M.. The Evolution of the Biofuel Science. Renewable and Sustainable Energy Reviews, v.76, p.1479-1484, 2017. DOI:

http://doi.org/10.1016/j.rser.2016.11.181

BRAZ, A. J. L.. Produção e caracterização de óleo vegetal e biodiesel de Girassol e de pinhão-manso. Dissertação (Mestrado em Engenharia Mecânica) - Universidade Federal Fluminense, Niterói, 2011.

DEMIRBAS, A.. Progress and recent trends in biofuels. Progress in Energy and Combustion Science, v.33, p.1-18, 2007. DOI: http://doi.org/10.1016/j.pecs.2006.06.001

FEROLDI, M.; CREMONEZ, P. A.; FEIDEN, A.; ROSSI, E.; NADALETI, W. C.; ANTONELLI, J.. Cultivo do Crambe: Potencial para Produção de Biodiesel. Revista Brasileira de Energias Renováveis, v.2, p.11-22, 2012.

GELLER, D. P.; ADAMS, T. T.; GOODRUM, J. W.; PENDERGRASS, J.. Storage Stability of Poultry Fat and Diesel Fuel Mixtures: Specific gravity and viscosity. Fuel, v.87, p.92102, 2008. DOI: http://doi.org/10.1016/j.fuel.2007.03.043

GULDHE, A.; SINGH, B.; RAWAT, I. BUX, F.. Synthesis of Biodiesel from Scenedesmus sp. By microwave and Ultrasound Assisted in situ Transesterification Using Tungstated zirconia as Asolid Acid Catalyst. Chemical Engineering Research and Design, v.92, p.1503-1511, 2014. DOI: http://doi.org/10.1016/i.cherd.2014.05.012

JOSHI, G.; PANDEY, J. K.; RANA, S.; RAWAT, D. S.. Challenges and opportunities for the application of biofuel. Renewable and Sustainable Energy Reviews, v.79, p.850-866, 2017. DOI: http://doi.org/10.1016/j.rser.2017.05.185

MAHMUDUL, H. M.; HAGOS, F. Y.; MAMAT, R.; ADAM, A. A.; ISHAK, W. F. W.; ALENEZI, R.. Production, Characterization and Performance of Biodiesel as an Alternative Fuel in Diesel Engines: A Review. Renewable and Sustainable Energy Reviews, v.72, p.497-509, 2017. DOI: http://doi.org/10.1016/i.rser.2017.01.001

MCHELIN, S.; PENHA, F. M.; SYCHOSKI, M. M.; SCHERER, R. P.; TREICHEL, H.; VALERIO, A.; LUCCIO, M.; OLIVEIRA, D.; OLIVEIRA, J. V.. Kinetics of ultrasound-assisted enzymatic biodiesel production from Macaúba coconut oil. Renewable Energy, v.76, p.388-393, 2015. DOI:

http://doi.org/10.1016/j.renene.2014.11.067

MEJIA, J. D.; SALGADO, N.; ORREGO, C. E.. Effect of blends of Diesel and Palm-Castor biodiesels on viscosity, cloud point and flash point. Industrial Crops and Products, v.43, p.791-
797, 2013. DOI:

http://doi.org/10.1016/j.indcrop.2012.08.026

OLIVEIRA, C. J.; SCHAFFNER R. A.; CREMONEZ P. A.; FEROLDI M., TELEKEN J. G.. Produção de Biodiesel a partir das Algas: uma revisão. Journal of Agronomic Sciences, v.3, p.202-222, 2014.

PAIVA, E. J. M.; SILVA, M. L. C. P.; BARBOZA, J. C. S.; OLIVEIRA, P. C.; CASTRO, H. F.; GIORDANI, D. S.. Non-edible babassu oil as a new source for energy production-a feasibility transesterification survey assisted by ultrasound. Ultrasonics Sonochemistry, v.20, p.833-838, 2013. DOI: http://doi.org/10.1016/j.ultsonch.2012.11.003

PARIDA, S.; SAHU, D. K.; MISRA, P. K.. Optimization of Transesterification Process by the Application of Ultrasound Energy Coupled with Diesel as Cosolvent. Journal of the Energy Institute, v.90, p.556-562, 2017. DOI: http://doi.org/10.1016/i.joei.2016.05.006

QUESSADA, T. P.; GUEDES, C. L. B.; BORSATO, D.; GAZZONI, B. F.; GALÃO, O. F.. Obtenção de Biodiesel a Partir de Óleo de Soja e Milho Utilizando Catalisadores Básicos e Catalisador Ácido. Enciclopédia Biosfera, Goiânia, v.6, n.11, 2010.

ROZINA, A. S.; AHMAD, M.; ZAFAR, M.; ALI, N.. Prospects and potential of fatty acid methyl esters of some non-edible seed oils for use as biodiesel in Pakistan. Renewable and Sustainable Energy Reviews, v.74, p.687-702, 2017. DOI: http://doi.org/10.1016/j.rser.2017.02.036

SARIN, A.; ARORA, R. SINGH, N. P.; SARIN, R.; MALHOTRA, R. K.; KUNDU, K.. Effect of Blends of Palm-Jatropha-Pongamia Biodiesels on Cloud Pointa Pour Point. Energy 34, p.20162021, 2009. DOI:

http://doi.org/10.1016/j.energy.2009.08.017

SILVA, I. M.. Caracterização de misturas de biodiesel de girassol com diesel, armazenadas em diferentes temperaturas e períodos. Dissertação (Mestrado em Engenharia Mecânica) - Universidade Federal Fluminense, Niterói, 2009.

SOUZA, C. D. R.; CHAAR, J. S.; SOUZA, R. C. R.; JEFFREYS, M. F.; SOUZA, K. S.; COSTA E. J. C.; SANTOS, J. C.. Caracterização físico-química das misturas binárias de biodiesel e diesel comercializados no Amazonas. Acta Amazônica, v.39, p.383388, 2009.

SU, Y.; SONG, K.; ZHANG, P.; SU, Y.; CHENG, J.; CHEN, X.. Progress of microalgae biofuel's commercialization. Renewable and Sustainable Energy Reviews, v.74, p.402411, 2017. DOI: http://doi.org/10.1016/i.rser.2016.12.078

TULCÁN, O. E. P.; PEREIRA, R. G.; FELLOWS, C. E.; ANDRADE, E. T.. Análises das propriedades de cinco tipos diferentes de triglicerídeos e seus correspondentes ésteres combustíveis 
(biodiesel). In: CONGRESSO NACIONAL DE ENGENHARIA

MECÂNICA, 6. Anais. Paraíba: 2010.

VASCONCELOS, A. F. F.. Conformidade de Misturas Binárias de Biodieseis Etílicos quanto aos Parâmetros Reológicos,

Fluidodinâmicos, Oxidativos e Carburantes. Tese

(Doutorado em Química) - Universidade Federal da Paraíba, João Pessoa, 2009.
WANG, H.; GAO, L.; CHEN, L.; GUO, F.; LIU, T.. Integration Process of Biodiesel Production from Filamentous Oleaginous Microalgae Tribonema Minus. Bioresource Technology, v.142, p.39-44, 2013. DOI:

http://doi.org/10.1016/j.biortech.2013.05.058

A CBPC - Companhia Brasileira de Produção Científica (CNPJ: 11.221.422/0001-03) detém os direitos materiais desta publicação. Os direitos referem-se à publicação do trabalho em qualquer parte do mundo, incluindo os direitos às renovações, expansões e disseminações da contribuição, bem como outros direitos subsidiários. Todos os trabalhos publicados eletronicamente poderão posteriormente ser publicados em coletâneas impressas sob coordenação da Sustenere Publishing, da Companhia Brasileira de Produção Científica e seus parceiros autorizados. Os (as) autores (as) preservam os direitos autorais, mas não têm permissão para a publicação da contribuição em outro meio, impresso ou digital, em português ou em tradução. 